\title{
PAPIESKA KOMISJA ARCHEOLOGII SAKRALNEJ Sto pięćdziesiąt lat działalności (1852-2002)
}

Sytuacja katakumb, poddawanych przez setki lat po ich odkryciu systematycznej eksploatacji i dewastacji przede wszystkim przez poszukiwaczy relikwii ${ }^{1}$, w 1. poł. XIX wieku była już opłakana. Doszło do tego, że jezuita Giuseppe Marchi (1795-1860), profesor Collegio Romano i dyrektor Museo Kircheriano, jeden $\mathrm{z}$ najznamienitszych badaczy wczesnego chrześcijaństwa ${ }^{2}$, uznał za konieczne zwrócić uwagę Ojca Świętego Grzegorza XVI (18311846) na różnego rodzaju nadużycia w działalności Custodia dei Sacri Cimiteri i Sagrista Pontificio, których zadaniem bylo czuwanie nad pracami prowadzonymi w katakumbach ${ }^{3}$. Zaniepokojony papież w 1842 r. stworzył nowy urząd Conservatore dei Sacri Cimiteri i powierzył tę funkcję ojcu Marchiemu ${ }^{4}$, który miał ukrócić samowolne poczynania dotychczasowych „strażników”. Niestety, okazało się, że było to zadanie ponad jego siły ${ }^{5}$. W sukurs pośpieszyli mu kontrolerzy, wyznaczeni do zbadania sytuacji w katakumbach przez następcę Grzegorza XVI - Piusa IX $(1850)^{6}$. To oni zasugerowali papieżowi, aby powołać do życia zatrudniającą osoby kompetentne instytucję, która objęlaby nadzór nie tylko nad katakumbami, ale i nad innymi zabytkami wczesnochrześcijańskimi Rzymu, i 8 maja 1851 r. przedstawili „Progetto di una Commissione

${ }^{1}$ Por. B. Wronikowska, Historia badań nad malowidtami z katakumb Rzymu - cz. 1, RH 29 (1981) z. 4, 81-98; A. Ferrua, La Pontificia Commissione di Archeologia Sacra, w: G. Matthiae i in., Arte, scienza e cultura in Roma cristiana, Bologna 1971, 355: „Le catacombe romane dalla fine del sec. XVI in poi erano diventate una miniera inesauribile dei corpi martiri".

${ }^{2}$ Por. R. Fausti, Documenti inediti sull'azione innovatrice del p. G. Marchi SJ ( +1860$)$ negli studi di archeologia, ,Rendiconti della Pontificia Accademia Romana di Archeologia” 19 (19421943) 105-179.

${ }^{3}$ Por. tamże, art. cyt., s. 131-133.

${ }^{4}$ Por. tamże, art. cyt., s. $120-122$.

${ }^{5}$ Por. tamże, art. cyt., s. 125, 140-142; A. Ferrua, I primordi della Commissione di Archeologia Sacra 1851-1852, „Archivio della Società romana di Storia patria” 91 (1968) 252n.

${ }^{6}$ Por. R. Giuliani, L'istituzione della Pontificia Commissione di Archeologia Sacra, w: Pontificia Commissione di Archeologia Sacra (1852-2002). Centocinquanta anni di tutela delle catacombe cristiane d'Italia, Città del Vaticano 2002, art. 2. 
di Archeologia Sacra"7 . Zaaprobowany przez papieża projekt stał się podstawą rozpoczętej natychmiast działalności komisji, w skład której weszli najdostojniejsi przedstawiciele Kościoła: biskup Porfirione mons. Giuseppe M. Castellani, arcybiskup Nisibis mons. Vincenzo Tizzani, prefekt Archivio Segreto mons. Marino Marini, o. Giuseppe Marchi SJ i o. Felice Profili, który do 1874 r. pełnił funkcję sekretarza ${ }^{8}$. Dnia 5 lipca tegoż roku regulamin Komisji został oficjalnie zatwierdzony przez kardynała Wikariusza roku i, zdaniem niektórych badaczy, to właśnie ten dzień można uważać za jej dies natalis". Przewodniczącym został mianowany Kardynał Wikariusz Generalny Costantino Patrizi.

Na posiedzeniu 20 listopada 1851 r. jej członkiem został Giovanni Battista De Rossi (1822-1894), słynny rzymski archeolog i twórca naukowych podstaw archeologii chrześcijańskiej, który wraz z o. Giuseppe Marchim, wyznaczony ,dalla Commissione alla direzione degli scavi degli antichi cimiteri"10, do końca XIX wieku nadawać będzie kierunek działalności Komisji (od 1874 r. jako jej sekretarz) ${ }^{11}$. Aktem prawnym powołującym Komisję do życia bylo pismo skierowane 6 stycznia 1852 r. w imieniu Ojca Świętego przez kardynała G. Antonellego do kardynała Wikariusza Costantino Patriziego ${ }^{12}$, a oficjalną wiadomość o jej powstaniu ogłoszono 7 lutego tegoż roku.

Wśród zadań, jakie przed Komisją postawiono, było m.in. utworzenie kolekcji starożytności chrześcijańskich w Museo Cristiano-Pio w pałacu papieskim na Lateranie (art. 12 i 22) ${ }^{13}$, a przede wszystkim badania naukowe zmierzające do poznania życia chrześcijan w pierwszych wiekach w katakumbach i kościołach o wczesnochrześcijańskiej genezie. Kładąc nacisk na badania ściśle naukowe Komisja nie zaniedbywała popularyzacji ich wyników. Pod jej egidą powstały zrzeszające miłośników starożytności chrześcijańskich stowarzysze-

${ }^{7}$ Por. V. Tizzani, Della Commissione di archeologia sacra, del museo Cristiano-Pio e dell'antica basilica di S. Clemente, Roma 1886, 7-11.

${ }^{8}$ Raffaella Giuliani, która obecnie pełni funkcję inspektora d/s katakumb rzymskich, tak przedstawia rolę sekretarza Komisji: ,il segretario di un dicastero della Santa Sede potrebbe definirsi il suo amministratore delegato, il dirigente operativo. L'etimologia della parola, infatti dal latino medievale, spiega che trattasi di colui che detiene gli affari piu importanti e anche riservati di un'amministrazione" (R. Giuliani, Mons. Pietro Crostarosa, Segretario della Commissione di Archeologia Sacra, "Il Massimo. Periodico quadrimestrale dell'Istituto Massimo" 80:2003, z. 2, s. 31).

${ }^{9}$ Por. Ferrua, I primordi, s. 256.

${ }^{10}$ Tamże, s. 261.

11 Por. A. Nestori, G.B. De Rossi e la Pontificia Commissione di Archeologia Sacra, w: Acta XIII Congressus Internationalis Archaeologiae Christianae, Split - Porec (25. 9. - 1. 10. 1994), t. 1, Città del Vaticano 1998, 185-222.

${ }^{12}$ Tekst listu: tamże, s. 257-259.

13 Por. G.B. De Rossi, „Bullettino di Archeologia Cristiana” 1876, s. 140; Tizzani, dz. cyt, s. 12-18. Relację z uroczystej inauguracji muzeum, którego otwarcia dokonal osobiscie Pius IX, znajdziemy w „Civiltà Cattolica” z 2 grudnia 1854 r., na stronie 569. 
nia: Società per le conferenze di archeologia cristiana oraz Collegium cultorum martyrum. Na mocy postanowień określających sposób działania Komisji niektóre z katakumb miały być dostępne dla zwiedzających, oczywiście pod nadzorem osób odpowiedzialnych za zachowanie w nienaruszonym stanie zwiedzanych obiektów. Na bilecie umożliwiającym wstęp do podziemnego cmentarza widnieją następujące uwagi: „1. należy zaopatrzyć się w mieście w małe świeczki; 2 . surowo zabronione jest dotykanie czegokolwiek co znajduje się na cmentarzu podziemnym i zabieranie stamtąd jakichkolwiek, nawet najmniejszych, przedmiotów lub cząsteczek kości"14

Do wyżej przedstawionej pierwszej grupy członków Komisji ${ }^{15}$ wkrótce przylączyli się mons. Giovanni Onesimo Luquet, profesor Tommaso Minardi, mons. Domenico Bartolini, prof. Pietro Ercole Visconti, mons. Camillo Amici i Francesco Tongiorgi. W latach 60-tych i 70-tych wśród czlonków Komisji znaleźli się m. in. Mariano Armellini, o. Luigi Bruzza, kardynał Raffaele Monaco La Valletta (przewodniczący) i Francesco Gatti, który od roku 1874 prowadził dzienniki wykopalisk. Od początku Komisja dysponowała grupą około 30 pracowników (fossori), którzy pod nadzorem inżyniera architekta (Francesco Fontana, Ignazio Cugnoni) prowadzili eksplorację archeologiczną i wykonywali prace konserwatorskie. Raporty publikowano na lamach „Civiltà Cattolica” oraz „Giornale di Roma”, a w latach 1863-1894 w wydawanym przez G. B. De Rossiego „Bullettino di archeologia cristiana”.

Prace prowadzone $w$ katakumbach pod patronatem Komisji przyniosły natychmiast nadspodziewanie bogate efekty ${ }^{16}$. Zwłaszcza G. B. De Rossi, ojciec ,archeologii chrześcijańskiej” 17 , którego niezaprzeczalną zasługą jest wypracowanie naukowych metod w badaniach nad katakumbami, byl autorem odkryć (głównie na cmentarzu Kaliksta), których znaczenia, fundamentalnego dla naszej wiedzy o początkach chrześcijaństwa, nie sposób przecenić ${ }^{18}$.

${ }^{14}$ Giuliani, dz. cyt., fig. 2.

15 Skład Komisji, od jej powstania do lat obecnych, podaję za A. Nestorim w wersji ograniczonej przeze mnie do postaci najbardziej znaczących, por. Gli Officiali della Pontificia Commissione di Archeologia Sacra, w: Pontificia Commissione di Archeologia Sacra (1852-2002), art. 5; tenże, Gli „Officiali” della Pontificia Commissione di Archeologia Sacra, w: Quaeritur Inventus Colitur. Miscellanea in onore di Padre Umberto Maria Fasola, B., Città del Vaticano 1989, 485-499.

${ }^{16}$ Por. relacja G.B. De Rossiego z wykopalisk przeprowadzonych w okresie od listopada 1851 do maja 1852 (cod. Vat. Lat. 10515), opublikowana w: Ferrua, I primordi, s. 270-277.

${ }^{17}$ Por. P.M. Baumgarten, Giovanni Battista De Rossi der Begründer der christlich-archäologischen Wissenschaft. Eine biographische Skizze, Köln 1892. Definicja „,archeologii chrześcijańskiej" - zob. H. Brandenburg, Archeologia cristiana, w: DPAC I 317-318.

${ }^{18}$ Por. A. Baruffa, Giovanni Battista de Rossi. L'archeologo esploratore delle catacombe, Città del Vaticano 1994; R. Giuliani (red.), Giovanni Battista De Rossi e le catacombe romane. Mostra fotografica e documentaria in occasione del 1. centenario della morte di Giovanni Battista de Rossi (1894-1994), Città del Vaticano 1994; V. Fiocchi Nicolai, G. B. De Rossi e le catacombe romane (1894-1994), w: Acta XIII Congressus, s. 205-222. 
W końcu XIX i na początku XX wieku w badaniach nad katakumbami aktywni byli przede wszystkim współpracownicy i uczniowie De Rossiego. Kilku z nich, jak: Michele Stefano De Rossi (sekretarz w latach 1891-1894), Enrico Stevenson i Orazio Marucchi, znalazło się również w składzie Commissione di Archeologia Sacra. Kontynuując badania mistrza w katakumbach, badacze ci tworzyli zarazem pierwsze syntezy, które znacząco oddziałały nie tylko na szerokie grono ówczesnych uczonych $z$ różnych europejskich środowisk, ale i na obraz pierwotnego chrześcijaństwa, funkcjonujący w potocznej świadomości rzesz czytelników. Po śmierci De Rossiego sekretarzem Komisji (na lata 1894-1902) mianowany został mons. Pietro Crostarosa. Jako pomocnika wiekowego już wówczas, ale nadal czynnego arcybiskupa Tizzani, w roku 1887 dokooptowano o. Germano da S. Stanislao. Przewodniczył wówczas Komisji kardynal Wikariusz L.M. Parocchi. Publikację wyników badań, którym patronowała Komisja, przeniesiono do „Nuovo Bullettino di Archeologia Cristiana", redagowanego przez E. Stevensona.

$\mathrm{Na}$ początku XX wieku w prace Komisji włączyli się epigrafik Giuseppe Gatti, architekt Giovanni Battista Giovenale, inżynier Guglielmo Palombi, Rudolf Kanzler (sekretarz od 1902 r.), Georg Schneider, Anton De Waal oraz kardynał Pietro Respighi (przewodniczący do roku 1913). W latach 20-tych jej członkiem został Joseph Wilpert, badacz katakumb i postać od dawna już na polu badań nad sztuką wczesnochrześcijańską wielce zasłużona, jako wydawca korpusów i autor studiów ikonograficznych ${ }^{19}$. W tym czasie wśród członków Komisji znaleźli się także Cosimo Stornaiolo, Pio Franchi de'Cavalieri, Enrico Josi, mons. Pio Paschini, o. Felice Grossi Gondi, mons. Giulio Belvederi, Bartolomeo Nogara, Attilio Profumo, mons. Carlo Respighi (sekretarz w latach 1918-1947) oraz kardynał Wikariusz Basilio Pompili, który zastąpił w funkcji przewodniczącego zmarłego w 1913 r. kardynała Pietro Respighi. Od roku 1922 w dokumentach Komisji pojawia się inżynier Francesco Fornari, który w roku 1924 został dyrektorem technicznym na miejsce inż. Palombi.

W 1924 r. Komisja rozpoczęła wydawanie nowego czasopisma „Rivista di Archeologia Cristiana", na łamach którego relacjonowane są do dzisiaj wszystkie przedsięwzięcia i odkrycia przez Komisję prowadzone, finansowane i firmowane.

Od roku 1925 w strukturze Komisji pojawiła się nowa funkcja - komisarz korespondent. Mianowani nimi zostali wówczas arcybiskup Algerii A.F. Leynaud, o. A.L. Delattre z Kartaginy, mons. J. P. Kirsch z Fryburga szwajcarskiego, mons. P. Battifol z Paryża, o. R. Maere z Leuven, F.J. Bulić ze Splitu, o. F. Naval y Ayérve z Madrytu, prof. A. Grier z Barcelony, ks. F.J. Dölger

19 Już 11 XI 1896 r. O. Marucchi wysunął kandydaturę Wilperta, ale została odrzucona, ponieważ E. Stevenson obawiał się, że "pel carattere del Wilpert si deve temere che voglia imporre le sue idee agli altri commissari” (za: Nestori, Gli „Officiali”, dz. cyt., s. 492). 
z. Münster oraz prof. J. Sauer z Fryburga niemieckiego. Nieco później dołączył do tej grupy Paolo Orsi, badacz katakumb Sycylii.

W 1925 r. Pius XI, „il grande mecenate di archeologia cristiana”20, uznał Komisję za instytucję Papieską (Pontificia), przyznał na jej działalność znaczne dotacje i przydzielil siedzibę w Rzymie, przy via Napoleone III, 1. Wtedy też określono ponownie jej kompetencje (w Motu Proprio „I primitivi cemeteri” di Pio XI. Della Pontificia Commissione di Archeologia Sacra e dal nuovo Pontificio Istituto di Archeologia cristiana, z dnia 11 XII 1925 r. I w dołączonym do niego Regulaminie Komisji), potwierdzone później w dwustronnych umowach zawieranych między Santa Sede i państwem włoskim ${ }^{21}$. Na mocy artykułu 33 Konkordatu zawartego w 1929 r. Pontificia Commissione di Archeologia Sacra (= PCAS) przejęła pieczę nad wszystkimi katakumbami, nie tylko w Rzymie, ale i w całej Italii. Po śmierci w 1931 r. Basilio Pompili, jej przewodniczącym został kardynał Francesco Marchetti Selvaggiani.

W 1932 r. z inicjatywy mons. Giulio Belvederi opublikowany został pierwszy katalog fotografii z kolekcji PCAS ${ }^{22}$. Obejmował on ok. 6000 zdjęć, które powstały w trakcie rozmaitych prac w katakumbach rzymskich. Od $1936 \mathrm{r}$. powiększający się stale zbiór przechowywany jest w Archiwum Fotograficznym Sióstr Benedyktynek przy katakumbie Pryscylli.

Komisja działała nieprzerwanie, prowadząc swe prace nawet w niezwykle trudnym okresie II wojny światowej. Tuż przed nią członkiem PCAS został mons. Johann Peter Kirsch, pierwszy rektor Papieskiego Instytutu Archeologii Chrześcijańskiej, a także mons. Alfonso Camillo De Romanis i dr Alessandro Carletti (po śmierci w 1979 r. zostanie zastąpiony przez syna, prof. Carlo Carletti). W 1941 r. członkiem Komisji mianowany został o. Antonio Ferrua, który od 1947 r. pelnil funkcję sekretarza (od 1971 r. sekretarza emerytowanego).

W okresie powojennym największe zasługi $w$ badaniach nad wczesnochrześcijańskim Rzymem położyli następujący członkowie PCAS: o. Antonio Ferrua, mons. Lucien de Bruyne, o. Umberto M. Fasola, prof. Carlo Pietrangeli, prof. Sandro Carletti, prof. Fernando Castagnoli, prof. Bruno M. Apolloni Ghetti, o. Agostino Amore, mons. Pietro Amato Frutaz, prof. Pasquale Testini. W 1951 r. Ojciec Święty mianował kardynała Clemente Micara przewodniczącym PCAS, w roku zaś 1962 inż. Mario Santa Maria zastąpił wiekowego inżyniera Fornari. W latach 60 -tych kilkakrotnie zmieniał się przewodniczący Komisji (kardynałowie Luigi Traglia i Angelo dell'Acqua, arcybiskup Koryntu

${ }^{20}$ Por. U.M. Fasola, Il catalogo dei reperti archeologici delle catacombe romane, „Rivista di Archeologia Cristiana" (dalej RivAC) 58 (1982) 223.

${ }^{21}$ Polski przekład Motu proprio i dolączonego doń Regulaminu Komisji zob. wyżej w dziale „Dokumenty” s. 19-29, umowy zas zob. Acta Apostolicae Sedis. Inter sanctam Sedem et Italiam Conventiones initae diebus 18 febr. et 15. nov. 1984, Città del Vaticano 1985.

22 Por. G. Belvederi, Elenco delle fotografie di Antichità Cristiana, Roma 1932. 
Gennaro Verolino). Wraz z nominacją mons. Verolino wygasła tradycja, zgodnie z którą Komisji przewodniczył kardynał Wikariusz Rzymu.

W 1973 r. staraniem o. Fasoli, od 1971 r. sekretarza PCAS, ukazała się druga edycja katalogu należącej do PCAS kolekcji fotografii, już trzykrotnie większej niż w latach 30-tych i uporządkowanej wedlug nowych i jasnych kryteriów ${ }^{23}$. $\mathrm{W}$ ostatnich dziesięcioleciach $\mathrm{w}$ archiwum nie tylko przybywaly nowe fotografie, które publikowano w latach 1975, 1980 i 1993 w kolejnych suplementach do katalogu, ale zmieniał się także ich format i jakość - obok czarno-biatych wykonywano odbitki kolorowe i przeźrocza. Najnowsza dokumentacja gromadzona jest już w siedzibie PCAS, której pracownicy zamierzają opracować katalog elektroniczny wszystkich fotografii będących w posiadaniu PCAS ${ }^{24}$.

W 1977 r. PCAS rozpoczęła, z inicjatywy o. Fasoli realizację programu katalogowania obiektów archeologicznych, znajdowanych i przechowywanych w katakumbach ${ }^{25}$. Są to na ogól chrześcijańskie i pogańskie epitafia, sarkofagi, zazwyczaj zachowane we fragmentach, oraz niezliczone drobne przedmioty ${ }^{26}$. Dotychczas sporządzono dziesiątki tysięcy fiszek inwentaryzując katakumby w Rzymie: Pretekstata, św. Sebastiana, Domitylli, Kaliksta, Felicyty, Pryscylli, św. Agnieszki, Marka i Marcelliana, Kommodylli, Cyriaki, św. Pankracego, oraz w Grottaferrata, św. Januarego w Neapolu i św. Jana w Syrakuzach ${ }^{27}$.

Prace w katakumbach pozarzymskich stanowią istotną część zadań PCAS. W latach 50-tych powstał inspektorat do spraw katakumb na terenie Wschodniej Sycylii, w ramach którego badaniem i konserwacją tamtejszych katakumb i hypogeów zajmowali się Giuseppe i Santi Luigi Agnello. Obecnie ich prace są kontynuowane - badania pod nadzorem Marii Rity Sgarlata (inspektor od 1995 r.) koncentrują się w Syrakuzach na obszarze katakumby św. Jana, a zwłaszcza rotund Antiochii i Adelfii oraz na cmentarzu Vigna Cassia ${ }^{28}$. Od 1998 r. trwa proces inwentaryzowania znalezisk pochodzących z wykopalisk Santi Luigi Agnello.

W 1984 r. przy PCAS powstal, kierowany do dziś przez Vincenzo Fiocchi Nicolai, inspektorat do spraw katakumb z rejonu Lazio ${ }^{29}$. W ramach realizo-

${ }^{23}$ Por. U.M. Fasola, Catalogo delle fotografie di antichità cristiana, Città del Vaticano 1973.

${ }^{24}$ Por. B. Mazzei, L'Archivio fotografico della Pontificia Commissione di Archeologia Sacra, w: Pontificia Commissione di Archeologia Sacra (1852-2002), art. 17.

${ }^{25}$ Por. Fasola, Il catalogo dei reperti archeologici, s. 221-226.

${ }^{26}$ Por. C. Salvetti, Il catatalogo degli oggetti minuti conservati presso la Pontificia Commissione di Archeologia Sacra, RivAC 54 (1978) 103-130; taż, Ritratti maschili conservati presso la PCA.S., w: Quaeritur Inventus Colitur, s. 715-734; A.M. Ramieri, Ritratti femminili conservati presso la Pontificia Commissione di Archeologia Sacra, w: tamże, s. 605-624.

${ }^{27}$ Por. F. Bisconti, La catalogazione dei materiali delle catacombe, w: Pontificia Commissione di Archeologia Sacra (1852-2002), art. 18.

${ }^{28}$ Por. M.R. Sgarlata, Le catacombe della Sicilia Orientale, w: Pontificia Commissione di Archeologia Sacra (1852-2002), art. 21.

29 Por. V. Fiocchi Nicolai, Le catacombe del Lazio, w: Pontificia Commissione di Archeologia Sacra (1852-2002), art. 20. 
wanego już od 1977 r. programu przeprowadzono prace wykopaliskowe i konserwatorskie w kilkunastu spośród 30-tu zachowanych katakumb ${ }^{30}$, a najważniejsze z nich (św. Krystyny w Bolsena, św. Eutycjusza koło Soriano nel Cimino, św. Senatora w Albano Laziale, św. Sawinilli w Nepi, św. Teodory w Rignano Flaminio, św. Wiktorii w Monteleone Sabino, Ad Decimum koło Grottaferrata, św. Hilarego Ad Bivium koło Valmontone) udostępniono zwiedzającym. Można zwiedzać również pozostałe katakumby Lazio, uzyskawszy uprzednio pozwolenie w biurze PCAS.

W roku 1987 Ojciec Święty Jan Pawel II mianował przewodniczącym Komisji mons. Mario Schierano. W roku następnym komisarzami zostali profesorowie Danilo Mazzoleni, Letizia Pani Ermini, Aldo Nestori, Giuseppe Zander oraz dr Valnea Scrinari Santa Maria. Na mocy porozumień nowego konkordatu, utworzono w roku 1988 kolejny inspektorat - dla Sycylii Zachodniej (z prof. Amedeo Tullio na czele), co umożliwiło PCAS, w porozumieniu z Soprintendenza di Palermo i Dipertimento di beni Culturali dell'Università di Palermo, podjęcie prac wykopaliskowych w katakumbie Porta d'Ossuna w Palermo ${ }^{31}$.

Ostatnie dziesięciolecia to okres intensywnych prac archeologicznych, prowadzonych $\mathrm{z}$ zastosowaniem najnowszych metod wykopaliskowych $\mathrm{i}$ badawczych (stratygrafia ${ }^{32}$, fotogrametria ${ }^{33}$ ), za zgodą Ministero per i Beni Culturali nie tylko w podziemiach katakumb, ale także w ich naziemnych częściach. Rezultatem tych prac były odkrycia, nierzadko spektakularne, takich monumentalnych obiektów, jak bazyliki: „cyrkowa” Marka w rejonie między Via Appia i Via Ardeatina, św. Mustioli w Chiusi, św. Hilarego w Valmontone, bazylika w Willi S. Faustino w Masa Martana. Znaczące wyniki przyniosły także badania w katakumbach i hypogeach Rzymu: m. in. przy Via Latina 135, przy via Dino Compagni, w ex vigna Chiaraviglio, Vibii, Quattro Oranti, św. Marcellina i Piotra, Pryscylli, ale i innych miejscowości w rejonie Lazio (m.in. Zotico przy Via Labicana, św. Wiktorii w Monteleone Sabino, św. Krystyny w Bolsena, św. Teodory w Rignano Flaminio, św. Senatora w Albano), w Umbrii (Villa di S. Faustino a Massa Martana), Toscanii (św. Mustioli w Chiusi, katakumba w Pianosa), Abruzzo (św. Wiktoryna koło Aquila, św. Justy koło Bazzano, w Castelvecchio Subequo), Puglii (w Venosa i Canosa), na Sardynii i Sycylii. Relacje z przeprowadzonych prac znaleźć można w kolejnych

${ }^{30}$ Por. V. Fiocchi Nicolai, I cimiteri paleocristiani del Lazio. I. Etruria Meridionale, Città del Vaticano 1988

${ }^{31}$ Por. R.M. Bonacasa Carra, Le necropoli paleocristiane di Palermo: aspetti, problemi ed ipotesi di ricerca, w: Quaeritur Inventus Colitur, s. 51-69.

32 Jako pierwszy metodę stratygraficzną w katakumbach zastosował o. U.M. Fasola w katakumbie S. Gennaro w Neapolu - por. R. Giuliani, Lo scavo delle catacombe, w: Pontificia Commissione di Archeologia Sacra (1852-2002), art. 7.

${ }^{33}$ Por. L. Reekmans, La photogrammétrie appliquée dans les catacombes romaines, w: Quaeritur Inventus Colitur, s. 641-659. 
tomach Attività della Santa Sede oraz w Atti della Pontificia Commissione di Archeologia Sacra, publikowanych na lamach „Rivista do Archeologia Cris-

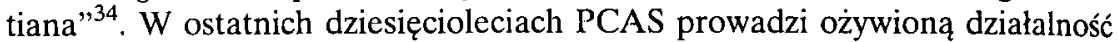
edytorską, publikując, w ramach kilku serii wydawniczych ${ }^{35}$, monografie katakumb rzymskich i pozarzymskich, akta sympozjów, a także innego rodzaju relacje $z$ działalności Komisji ${ }^{36}$.

Ważnym impulsem dla wzmożenia wysilków mających na celu odnowienie katakumb i udostępnienie ich, przy'najmniej w pewnym zakresie, zwiedzającym był Jubileusz 2000 roku. W ramach przygotowań do Roku Świętego PCAS opublikowała przedruk jednego $\mathrm{z}$ fundamentalnych dzieł $\mathrm{z}$ dziedziny archeologii chrześcijańskiej, które ukazało się w roku 1632 - Roma sotterranea Antoniego Bosio, nazywanego „Kolumbem podziemnego Rzymu” ${ }^{\text {37 }}$. Do dziś niezastąpione, słusznie uchodzi za niezbędne narzędzie pracy wszystkich badaczy katakumb $^{38}$.

Do najbardziej znaczących form dzialalności Komisji w ostatnich latach należały szeroko zakrojone prace przy oczyszczaniu i konserwacji malowidel katakumbowych, prowadzone (m.in. przez Raffaelę Giuliani, Barbarę Mazzei) przy zastosowaniu nowoczesnych metod i technologii ${ }^{39}$. Kierował nimi obecny sekretarz PCAS Fabrizio Bisconti ${ }^{40}$, a podjęto je w katakumbach Pryscylli ${ }^{41}$, św. Marcellina i Piotra ${ }^{42}$, przy Via Dino Compagni ${ }^{43}$, Poncjana, Generosy,

${ }^{34}$ Por. najnowszą bibliografię w: F. Bisconti - D. Nuzzo, Scavi e restauri nelle regione della „Velata" in Priscilla, RivAC 78 (2001) 7-10.

${ }^{35} \mathrm{~Np}$. Guide delle catacombe di Roma; Collezione della Pontificia Commissione di Archeologia Sacra; Catacombe di Roma e d'Italia; Studi e ricerche; Scavi e restauri.

${ }^{36}$ Wykaz publikacji można znaleźć w internecie (http://www.vatican.va/roman_curia).

37 Por. G.B. De Rossi, La Roma sotterranea cristiana, t. 1, Roma 1864, 43.

38 Por. V. Fiocchi Nocolai, Presentazione, w: A. Bosio, Roma sotterranea, Roma 1998, 12.

39 Por. B. Mazzei - S. Cascioli - M.G. Patrizi, Interventi di restauro nelle catacombe romane: documentazione e conservazione, w: Seminari di Archeologia Cristiana 1995-1996, RivAC 73 (1997) 288-290; Dieci anni di restauro nelle catacombe romane. Bilancio, esperienze e interventi conservativi delle pitture catacombali, a cura della PCAS, Città del Vaticano 2000; R. Giuliani (ed.), La conservazione delle pitture nelle catacombe romane. Acquisizioni e prospettive. Atti della giornata di studio (Roma, 3 marzo 2000), Città del Vaticano 2002.

${ }^{40}$ Por. F. Bisconti, Novità figurative nelle catacombe romane: scoperte e restauri, w: Atti del VII Congresso Nazionale di Archeologia Cristiana, Cassino 20-24 settembre 1993 ( w druku).

${ }^{41}$ Por. F. Bisconti, La Madonna di Priscilla: Interventi di restauro ed ipotesi sulla dinamica decorativa, RivAC 72 (1996) 7-34; B. Mazzei, Il cubicolo dell'Annunciazione nelle catacombe di Priscilla. Nuove osservazioni alla luce dei recenti restauri, RivAC 75 (1999) 233-280.

42 Por. R. Giuliani, Il restauro del cubicolo detto „degli Atleti" nella catacomba dei SS. Marcellino e Pietro sulla sulla via Labicana, w: Acta XIII Congressus, t. 3, s. 317-328; taż, Il restauro del cubicolo detto „delle Stagioni” nella catacomba dei SS. Marcellino e Pietro sulla sulla via Labicana, RivAC 72 (1996) 35-64.

${ }^{43}$ Por. F. Bisconti - B. Mazzei, Il cubicolo di Sansone nell'ipogeo di via Dino Compagni alla luce dei recenti interventi di restauro, „Mitteilungen zur christlichen Archäologie” 5 (1999) 45-73. 
Pretekstata ${ }^{44}$, Kaliksta, św. Sebastiana, Jordanów, Domitylli ${ }^{45}$, w ex vigna Chiaraviglio, w hypogeum Aureliuszy. Obecnym przewodniczącym PCAS jest Mons. Francesco Marchisano. Siedziba mieści się nadal w Rzymie, przy Via Napoleone III, 1 (pcomm.arch@arcsacra.va).

\section{PONTIFICIA COMMISSIONE DI ARCHEOLOGIA SACRA 150 anni dell'attività (1852-2002)}

(Riassunto)

L'articolo presenta il profilo dell'attività della Pontificia Commissione di Archeologia Sacra dal momento della sua fondazione - frutto dell'iniziativa degli studiosi delle antichità cristiane, preoccupati dello stato delle catacombe continuamente devastate dai ricercatori delle reliquie, fino ai tempi nostri. Tra i compiti che la Commissione si assegnava la più importante fu la gestione degli scavi e delle ricerche nelle catacombe e nelle chiese paleocristiane, compresa la pubblicazione dei frutti di queste. Nell'articolo vengono presentate le iniziative dei membri della Commissione che avevano come scopo ampliamento della sua attività: l'estensione delle ricerche sui cimiteri (anche quelli sub divo) e sulle chiese di tutto il territorio italiano; la creazione di un archivio e la pubblicazione dei cataloghi delle fotografie appartenenti a PCAS; la registrazione degli oggetti archeologici rinvenuti e conservati nelle catacombe; i lavori di ripulitura e di conservazione degli affreschi nelle catacombe; la facilitazione dell'accesso ai monumenti paleocristiani ai visitatori; l'attività editoriale.

${ }^{44}$ Por. tenże, La „coronatio" di Pretestato. Storia delle manomissioni del passato e riflessioni sui recenti restauri, RivAC 73 (1997) 7-49; S. Cascioli - B. Mazzei - M.G. Patrizi, Il restauro della coronatio nel cimitero di Pretestato. Resoconto degli interventi conservativi, tamże, s. 51-63.

${ }^{45}$ Por. R. Giuliani, Il restauro dell'arcosolio di Veneranda nelle catacombe di Domitilla sulla Via Ardeatina, RivAC 70 (1994) 61-87. 